6. Библер В.С. Мышление как творчество (Введение в логику мысленного диалога). М.: Политиздат, 1975. 399 c.

7. Бахтин М.М. Вопросы литературы и эстетики. Исследования разных лет. - М.: «Худож. лит.», $1975 .-504$ с.

8. Выготский Л.С. Психология искусства. - Ростов н/Д.: изд-во «Феникс», 1998. - 480 с.

9. Шкловский В.Б. Гамбургский счет: Статьи - воспоминания - эссе (1914 - 1933). Два первых десятилетия. [Электронный ресурс]. URL: http://litrus.net/book/read/1234.

10. Флоренский П.А. Культ, религия и культура (из богословского наследия) // Труды Московской Патриархии. - М., 1977. - Вып. 17. - С. 101-119.

\title{
Моисеева Н.А. \\ Применение основ технологии экспертных систем в вузовском курсе информатики
}

Омский государственный технический университет

(Россия, Омск)

doi: 10.18411/trnio-09-2021-54

\section{Аннотация}

В статье предлагается применение основ технологии экспертных систем в вузовском курсе информатики. Обосновано, что решение учебно-познавательных задач с использованием продукционной модели знаний способствует развитию системного мышления у студентовпервокурсников. Приведен пример задачи, в которой рассматривается процесс формирования решений с помощью экспертной системы в среде электронной таблицы Excel.

Ключевые слова: интеллектуальные информационные технологии, технология экспертных систем, продукционная модель знаний, вузовский курс информатики.

\section{Abstract}

It is proposed the application of the basics of expert systems technology in the university course of Computer Science. It is substantiated that the solution of educational and cognitive tasks using knowledge production model contributes to the development of systems thinking in first-year students. It is given an example of a problem in which it is considered process of forming decisions by means of expert systems technology in Excel spreadsheet.

Keywords: intelligent information technology, expert systems technology, knowledge production model, university course of Computer Science.

В настоящее время перед системой профессиональной подготовки специалистов стоит ряд серьёзных проблем: повышение качества обучения, развитие системного мышления, личностное развитие, цифровизация образования, основанная на внедрении современных информационных и коммуникационных технологий в процесс обучения. Одна из главных особенностей цифровизации на современном этапе её развития заключается в том, что в основу программных средств цифровизации будут положены программное обеспечение и онлайн-сервисы, базирующиеся на достижениях в области искусственного интеллекта (ИИ). В этой связи, определяется уровень требований к профессиональной подготовке современного специалиста. Одно из требований состоит в умении применять приложения ИИ в своей будущей профессиональной деятельности.

Включение основ интеллектуальных информационных технологий (ИИТ) в требования к содержанию образования и уровню подготовки студентов в высших учебных заведениях весьма актуально в плане подготовки студентов к успешной профессиональной деятельности в современном информационном обществе. Профессиональные задачи большинства специалистов заключаются в принятии решений. Для принятия решений предназначена обработанная информация - знания. В свою очередь, знания связаны с данными, основываются на них, но представляют результат мыслительной деятельности человека, обобщают его опыт, полученный в ходе выполнения какой-либо практической деятельности [1]. 
Моделирование знаний с помощью компьютера возможно через использование ИИТ, под которыми понимаются информационные технологии, базирующиеся на методологических принципах и подходах ИИ, как одного из направлений информатики, цель которого разработка программно-аппаратных средств, позволяющих ставить и решать задачи, традиционно считающиеся интеллектуальными. В настоящее время принято считать интеллектуальными задачи, которые на современном этапе не поддаются алгоритмизации, и для решения которых требуются манипуляции с нечёткими, неконкретными, ненадёжными, расплывчатыми знаниями. Современный подход к решению интеллектуальных задач базируется на алгоритмах и моделях ИИ [1].

Согласно передовой педагогической мысли, важнейшей задачей высшего образования является подготовка специалистов нового качества, которым нужно передавать не столько информацию, как собрание готовых ответов, сколько метод её получения, анализа и прогнозирования. Целесообразно организовать поз-навательную деятельность студентов в процессе обучения на принципах системного анализа, что в свою очередь способствует формированию системного мышления обучаемых. Мыслить системно - общественно осознанная потребность.

Рассмотрим более подробно один из вариантов использования ИИТ - технология экспертных систем при решении задач, направленных на принятие решений в условиях неопределённости. Подобные задачи рекомендуется решать со студентами в рамках изучения таких разделов вузовского курса «Информатика» как «Программные средства реализации информационных процессов» и «Модели решения функциональных и вычислительных задач».

В качестве программного средства ИИТ при решении учебно-познавательных задач такого рода рекомендуется использовать электронную таблицу (ЭТ) Excel. Это обусловлено тем, что интеллектуализация ЭТ позволяет после ввода числовых данных в таблицу автоматически получать в ней не только числовой результат, но и символьную оценку ситуации. Таким образом, формализованные знания анализируемой предметной области могут быть занесены в компьютерную систему и обработаны, т. е. получена информационная модель решаемой задачи и интерпретирована [2].

Пример 1. Рассмотрим процесс формирования решений с помощью экспертной системы, ориентированной на процессы инвестирования. Допустим, перед руководством предприятия возникла проблема принятия решения о вложении средств в акции другого предприятия. Сформулируем гипотезу следующим образом: акции предприятия $\mathrm{N}$ являются перспективными. Тогда задача состоит в расчёте коэффициента определённости данной гипотезы от 0 до 1. Лицо, принимающее решение, представляет знания о данном предприятии в виде дерева вывода, которое представлено на рис. 1. Дерево вывода имеет два уровня и содержит три продукционных правила.

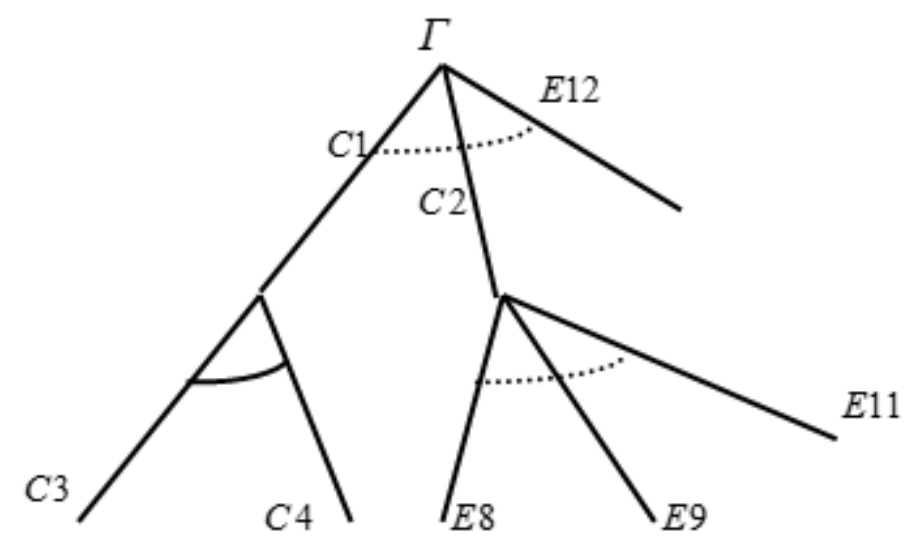

Рисунок 1. Фрагмент дерева вывода 
Подобные схемы представления причинно-следственных связей широко используются для анализа сложных систем. Когда когнитивная модель некоторой ситуации построена, необходимо проверить, насколько эта модель адекватна реальной ситуации. Такая проверка осуществляется следующим образом: допустим, что между базисными (фундаментальными) факторами, являющимися вершинами графовой модели, существуют отношения, которые можно трактовать как непреложные факты в рассматриваемой предметной области. Это отношение, как правило, формируется в виде продукиий, или продукиионной модели знаний, типа:

ЕСЛИ $\mathbf{X}_{1} V \mathbf{X}_{2}$ V... $\mathbf{X}_{\mathrm{k}}$, ТО В, где

$\mathbf{X}_{\mathbf{k}}$ - некоторая характеристика базисного фактора $\mathbf{V i ,}$

В - заключение.

Коэффициенты определённости условий С3, C4, E8, E9, E11 и Е12 ставятся лицом, принимающим решение (см. рис. 2), а остальные - вычисляются. Коэффициент определённости правила ставится лицом, принимающим решение (см. рис. 3). Для отображения степени влияния условий - коэффициенты определённости условий используется совокупность лингвистических переменных типа «сильно», «умеренно», «слабо» и т. п. Такой совокупности лингвистических переменных соответствует числовая шкала $[0,1]$. Это та качественная информация, которая, собственно, и отличает вышерассмотренную систему формирования решений от формальных методов.

\begin{tabular}{|c|c|c|c|c|}
\hline & $A$ & $B$ & C & D \\
\hline 1 & $\begin{array}{c}\text { Уровень } \\
\text { дерева }\end{array}$ & $\begin{array}{c}\text { Номер } \\
\text { правила }\end{array}$ & Содержание правила & $\begin{array}{c}\text { Козффишент } \\
\text { определённости } \\
\text { правила }\end{array}$ \\
\hline 2 & 1 & 1 & $\begin{array}{l}\text { ЕСЛИ С1 ИлШ С2 भлШ } \\
\text { Е12, ТО Г }\end{array}$ & 0,8 \\
\hline 3 & \multirow{2}{*}{2} & 2 & ЕСЛИ С3 II C4, ТО $\mathrm{Cl}$ & 0,7 \\
\hline 4 & & 3 & 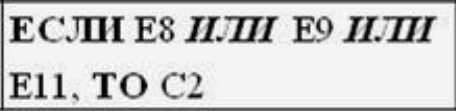 & 0,8 \\
\hline
\end{tabular}

Рисунок 2. Правила дерева вывода

\begin{tabular}{|c|c|c|c|}
\hline & A & B & C \\
\hline 1 & $\begin{array}{c}\text { Обозначение } \\
\text { узла }\end{array}$ & Содержание узла в дереве вывода & $\begin{array}{l}\text { Коэффициент } \\
\text { определённости }\end{array}$ \\
\hline 2 & $\Gamma$ & Акции покупать & \\
\hline 3 & C1 & $\begin{array}{l}\text { В текущем году прибыьл предприятия } \\
\text { не сншкалась }\end{array}$ & \\
\hline 4 & $\mathrm{C} 2$ & Риск потерь средств низкий & \\
\hline 5 & C3 & Выручка в текущем году не сншжалась & 0,4 \\
\hline 6 & $\mathrm{C} 4$ & Затраты не возросли & 0,6 \\
\hline 7 & E8 & Репутация предприятия высокая & 0,7 \\
\hline 8 & E9 & $\begin{array}{l}\text { Отдача от вложеншй больше уровня } \\
\text { инфлящи }\end{array}$ & 0,4 \\
\hline 9 & E11 & Цена акций допустимая & 0,3 \\
\hline 10 & E12 & $\begin{array}{l}\text { Стоимость акционерного капштала на } \\
\text { акцшо не меньше её цены }\end{array}$ & 0,5 \\
\hline
\end{tabular}

Рисунок 3. Расшифровка обозначений в дереве вывода 
Коэффициент определённости рассчитывается по соответствующим правилам. Полученное значение интерпретируется экспертной системой в привычной для человека форме - на естественном языке. Представим данную интерпретацию полученного результата в табличной форме (см. рис. 4). Механизм логического вывода созданной экспертной системы поддерживается стандартной логической функцией ЕСЛИ() ЭТ Excel.

\begin{tabular}{|l|c|c|}
\hline \multicolumn{1}{|c|}{$\begin{array}{c}\text { Оценка } \\
\text { перспективности }\end{array}$} & \multicolumn{2}{|c|}{ Диапазон } \\
\cline { 2 - 3 } & $\begin{array}{c}\text { начало } \\
\text { диапазона }\end{array}$ & $\begin{array}{c}\text { конец } \\
\text { диапазона }\end{array}$ \\
\hline $\begin{array}{l}\text { Акции предприятия N } \\
\text { являются перспективными }\end{array}$ & 0,75 & 1 \\
\hline $\begin{array}{l}\text { Средний уровень } \\
\text { перспективности акций } \\
\text { предприятия N }\end{array}$ & 0,55 & 0,74 \\
\hline $\begin{array}{l}\text { Низкий уровень } \\
\text { перспективности акций } \\
\text { предприятия N }\end{array}$ & 0 & 0,55 \\
\hline
\end{tabular}

Рисунок 4. Интерпретация результатов

При решении учебно-познавательных задач такого рода формируется системное мышление, поскольку многие операции, используемые в компьютерной обработке знаний, имеют много общего с мыслительными операциями человека, характеризующие системное мышление, например, анализ, синтез, индукция, дедукция и т. д.

Таким образом, обучение ИИТ на примере основ технологии ЭС позволяет формировать системное мышление студентов, являющимся одним из критериев успешности адаптации будущего специалиста в современном динамически развивающемся информационном обществе.

$$
* * *
$$

1. Башмаков А. И., Башмаков И. А. Интеллектуальные информационные технологии. - М.: Изд-во МГТУ им. Н. Э. Баумана, 2005. - 304 с.: ил.

2. Настащук Н. А. Развитие учебно-познавательной компетенции у будущих экономистов в процессе обучения интеллектуальным информационным технологиям: диссертация кандидата педагогических наук: 13.00 .02 / Н. А. Настащук. - Омск, 2009. - 199 с.

Моисеева Н.А. ${ }^{1}$, Чувикова В.В. ${ }^{2}$

Современный взгляд на активизацию познавательной деятельности студентов технических вузов (на примере будущих IT-специалистов)

${ }^{1}$ Омский государственный технический университет

(Россия, Омск)

${ }^{2}$ Институт международных экономических связей

doi: 10.18411/trnio-09-2021-55

(Россия, Москва)

\section{Аннотация}

В статье предлагается современный взгляд на решение проблемы активизации познавательной деятельности студентов технических вузов. Выявлена специфика учебного процесса обучающихся. Обосновано экспериментально, что применение инновационных методов и форм обучения способствует повышению активизации познавательной активности студентов. На основе полученных результатов сформулированы методические рекомендации, направленные на активизацию познавательной деятельности будущих IT-специалистов.

Ключевые слова: познавательная деятельность, инновационные методы и формы обучения, практико-ориентированные задачи, ІТ-специалист. 